\title{
Probability and mitigation of vessel encounters with North Atlantic right whales
}

\author{
Angelia S. M. Vanderlaan ${ }^{1}$, James J. Corbett ${ }^{2, *}$, Shannon L. Green ${ }^{2}$, \\ John A. Callahan ${ }^{3}$, Chengfeng Wang ${ }^{2}$, Robert D. Kenney ${ }^{4}$, Christopher T. Taggart ${ }^{1}$, \\ Jeremy Firestone ${ }^{2}$
}

\author{
${ }^{1}$ Dalhousie University, Department of Oceanography, Halifax, Nova Scotia B3H 4J1, Canada \\ ${ }^{2}$ University of Delaware, College of Marine and Earth Studies, Robinson Hall, Newark, Delaware 19716, USA \\ ${ }^{3}$ University of Delaware, Information Technologies, Newark, Delaware 19716, USA \\ ${ }^{4}$ University of Rhode Island, Graduate School of Oceanography, Narragansett, Rhode Island 02882, USA
}

\begin{abstract}
Successful mitigation of vessel-whale encounters requires quantitative estimates of vessel strikes, how strike rates change over time, where strikes are most likely to occur, and options for minimizing strikes. In addressing these issues, we first demonstrate a 3- to 4 -fold increase in the number of reported large whale-vessel strikes worldwide from the early 1970 s to the early 2000 s, corresponding to a 3 -fold increase in the number of vessels in the world fleet that is paralleled by an increase in vessel tonnage and speed. Second, we estimate a $50 \%$ chance of 14 or more annual vessel-strike reports worldwide between 1999 and 2002. For North Atlantic right whales Eubalaena glacialis, we estimate a $60 \%$ chance of observing at least 1 right whale death from vessel strike. Adjusting for undetermined causes of death and unobserved deaths, we estimate a 10 -fold increase (from 1 to 10) in the expected annual number of fatal ship strikes. Third, we evaluate the eastern United States geographic distribution of right whales and vessels to calculate relative probabilities of vessel-whale encounters among 3 major right whale habitats. We determine that the Southern Calving Ground poses the greatest threat of a vessel strike: 1.6- and 7-fold greater than in Cape Cod Bay and the Great South Channel, respectively. Finally, for the Great South Channel region we present a quantitatively determined vessel-traffic routing option that would achieve a $39 \%$ reduction in vessel-whale encounter probabilities. The methods employed in assessing encounter probabilities and vessel-routing options can be applied elsewhere to enhance the conservation of endangered and threatened species that suffer vessel-strike mortality.
\end{abstract}

KEY WORDS: Right whale $\cdot$ Eubalaena glacialis - Vessel $\cdot$ Ship $\cdot$ Strike $\cdot$ Encounter $\cdot$ Mortality · Mitigation · Routing

- Resale or republication not permitted without written consent of the publisher

\section{INTRODUCTION}

The North Atlantic right whale Eubalaena glacialis is one of the most endangered large whale species in the world (Caswell et al. 1999, Kraus et al. 2005). Whaling diminished their number considerably (Aguilar 1986) and despite legal protection from whaling since the 1930s, the number of right whales ${ }^{1}$ remains small with contemporary population estimates at $\sim 350$ individuals (Kraus et al. 2005). The majority of documented right whale injuries and deaths are attributable to ocean-going vessel strikes (Kraus et al. 2005), and such human-induced mortality particularly limits population growth for a species at critically low abundance (Clapham et al. 1999). If population growth and death rates, particularly humaninduced mortality (Fujiwara \& Caswell 2001), follow

\footnotetext{
1Two other species of right whales exist: North Pacific (E. japonica) and southern (E. australis) right whales (Rosenbaum et al. 2000). The term 'right whale' in this paper refers to the North Atlantic right whale (E. glacialis)
} 
recent trends, species extinction is likely within $200 \mathrm{yr}$ (Caswell et al. 1999). Minimizing the probability of vessel strikes to right whales presents a primary challenge for managers charged with implementing plans for the recovery of this endangered species (e.g. NOAA 2008a). Secondarily, managers should seek to minimize vessel strikes in a manner that also minimizes economic impacts and other disruptions to commercial shipping interests.

The threat of a vessel strike is not unique to the right whale. International efforts exist to conserve cetaceans in regions of the world other than the North Atlantic (ACCOBAMS 2007). Other large whales, including fin whales Balaenoptera physalus, humpback whales Megaptera novaeangliae, and minke whales Balaenoptera acutorostrata, are frequent victims of vessel strikes (Laist et al. 2001, Jensen \& Silber 2003), although on a per capita basis the right whale is most prevalent as a victim (Vanderlaan \& Taggart 2007).

Over the past 5 decades, the number of commercial vessels in the world fleet has tripled, with the greatest rate of increase occurring in the 1970s (Fig. 1). The increase in vessel number is paralleled by an increase in average ship tonnage and speed (Kite-Powell 2001, LMIS 2002, Corbett \& Koehler 2003, Eyring et al. 2005). Over the same period, the number of large whales reported struck by vessels has also increased approximately 3 -fold, although there is considerable inter-annual variability (Fig. 1).

According to the 1972 to 2006 worldwide observational data (see subsection 'Historical data'), vessel

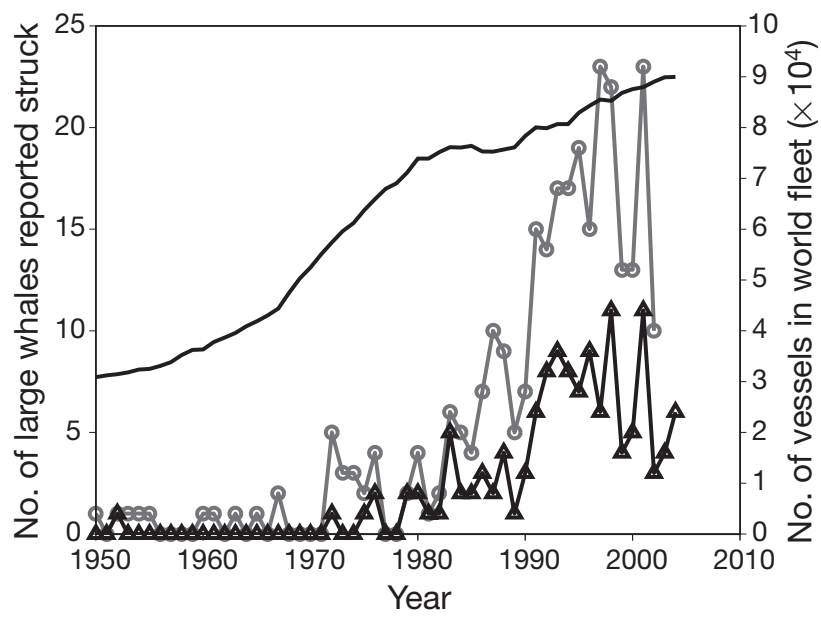

Fig. 1. Increases in the number of reported large-whale vessel strikes worldwide (open circles) and along the US East coast (triangles) complied from Best et al. (2001), Laist et al. (2001), Jensen \& Silber (2003), Cole et al. (2005, 2006), and the increase in the number of vessels over 100 gross tonnes (solid black line) in the world fleet over the period 1950 to 2002 inclusive (Colton 2004) strikes to right whales along the East coast of the USA are frequently reported in the vicinity of Cape Cod Bay, the adjacent Great South Channel, and the southern calving ground. Regions in Canadian waters are also of concern for vessel strikes.

In the USA, emergency measures have been recommended to protect the right whale, including reduced speeds and re-routing of commercial and military vessels (Kraus et al. 2005). Recently, the National Oceanic and Atmospheric Administration (NOAA) issued a series of notices of intent to reduce vessel-strike incidents (NOAA 2004, 2006, 2008a), and recent action has been taken (NOAA 2008b). In Canada, vessel rerouting for right-whale protection in the Grand Manan (Bay of Fundy) and Roseway (SW Scotian Shelf) basin habitats has been implemented (IMO 2003, IMO 2007, Vanderlaan et al. 2008).

Successful vessel-strike mitigation requires quantitative estimates of vessel-strike rates, their temporal variation, and where they are most likely to occur. Here, we estimate minimum temporal and regional probabilities of vessels striking large whales using all available worldwide data and then focus on the right whale along the east coast of North America. We then use density estimates of number per unit area for right whales and vessels along the east coast of the USA to determine the relative probability of vessel and whale encounters among 3 regions. We use these results to propose a vessel traffic routing option designed to reduce encounter probability. Importantly, this option is derived from explicit and quantitative methods for reducing encounter probabilities.

\section{MATERIALS AND METHODS}

Analyses. We conducted 4 related analyses focused on (1) Poisson model estimation of vessel-strike rates on large whales using historic data; (2) bootstrap sampling with the Poisson model using historic right-whale vessel-strike data; (3) spatially resolving relative encounter probabilities using vessel data and right whale survey data; and (4) designing vessel traffic rerouting to reduce vessel and right whale encounters.

Historical data and Poisson model estimation. The probability of a vessel and right whale encounter is asymmetric due to the small number of right whales relative to the large number of vessels that transit right whale habitat and migratory corridors; i.e. the probability that a given right whale ( 1 of order $10^{2}$ ) will be struck is $\sim 250$ times more likely than that of a given vessel ( 1 of order $10^{4}$ ) being involved. To use the Poisson probability distribution to model the probability of vessels striking whales requires 4 assumptions to be met (Morgan \& Henrion 1990, Clemen \& Reilly 2001): 
(1) a vessel striking a whale can occur at any time or place along a vessel route within a given region of interest, assuming whales are present, (2) the probability of a strike is small; i.e. a rare event, (3) vesselstrikes are independent events, and (4) the average number of events over time can be considered constant, or at least so over defined periods. We also assume (5) that the number of whales is unchanging over the periods considered; an assumption that may not be valid for each period (e.g. Caswell et al. 1999).

We use all worldwide historical vessel strike data to estimate the probability of a vessel striking a large whale; primarily baleen whales (compiled from Best et al. 2001, Laist et al. 2001, Jensen \& Silber 2003, Cole et al. 2005, 2006, M. J. Moore unpubl. data). Dates, locations, species, and descriptions of vessel-strikes and whale injuries were examined to ensure no duplication of records. We calculate the Poisson parameter $(\mu)$ that represents the expected (average) number of whalestrike reports $(n)$ per year over a given period $(T, \mathrm{yr})$ within a specified region according to:

$$
\hat{\mu}=\frac{n}{T}
$$

Estimates of $\mu$ likely underestimate the actual number of vessel strikes for a given period and region because each whale that is killed (or injured and subsequently dies) as a result of a vessel strike is not necessarily discovered or positively identified as being struck (Kraus et al. 2005). Thus, the probability $(P)$ that $X$ strikes will occur in a given year in a given region is calculated as:

$$
P(X=k \mid \hat{\mu})=\frac{\exp ^{-\hat{\mu}} \cdot \hat{\mu}^{k}}{k !}
$$

where $k=0,1,2, \ldots$ and $\hat{\mu}>0$. Aggregating the Poisson probabilities allows us to generate the cumulative distribution function (CDF) for a given period and region (defined below).

Following an examination of the worldwide data by region, we determined that the east coast of the USA large-whale vessel-strike data likely present the most complete annual series of consistent reporting from 1972 onward. We used these data to determine periods of stationarity (relative invariance) in the number of vessel strikes reported per annum (to meet Assumption 4 above). We used Webster's method to detect discontinuities in the series (Legendre \& Legendre 1998) based on a $4+4$ smoothing window-width and $\alpha=0.1$ for assigning significant discontinuity. Four periods of stationarity were determined: 1972 to 1979,1980 to 1989, 1990 to 1998, and 1999 to 2002, each inclusive. These same periods of stationarity are used for all analyses as they reflect the worldwide data (Fig. 1). We also examine an extended fourth period to cover 1999 to 2006 for right whales only using available data from Cole et al. (2005, 2006) and M. J. Moore (unpubl. data).
We calculate $\hat{\mu}$ to estimate vessel strike probabilities based on the above data for all large whale species across 3 geographic regions (worldwide, North America east coast, and USA east coast only) and for right whales in the North America east coast region.

Bootstrap estimation of Poisson parameter. We resample a subset of the above data using only those data derived from necropsied right whales for the period 1991 through 2002 (Moore et al. 2004) to estimate $\mu_{i}$ the average number of right whale deaths resulting from vessel strikes. Using bootstrap re-sampling with replacement, $\mathrm{n}=1000$, we calculate the annual number of deaths from vessel strikes and estimate the CDFs and the associated 95\% CIs using the Poisson model and the average value of $\hat{\mu}$.

Conservative probability estimates that a given number of right-whale deaths, attributable to vessel strikes $(Z)$, will occur within a year are based on the documented vessel-strike deaths adjusted by 2 correction factors that allow us to bound the range of the $\hat{\mu}$ estimates. The first is related to undetermined causes of death (Moore et al. 2004), and the second is related to the $17 \%$ detection rate of right-whale deaths (Kraus et al. 2005). The first of the 2 estimates is:

$$
Z_{1}=X+\psi W
$$

where $X$ is the number of all found-dead right whales where death is attributed to vessel strike, $W$ is the number of all found-dead right whales and $\psi$ is an estimate of the proportion of necropsied right whales where the unknown cause of death can be attributed to a vessel strike ( $\psi=2 / 30$, Moore et al. 2004). The second estimate is:

$$
Z_{2}=X+W\left(\psi+\frac{a Q}{1-Q}\right)
$$

where $a$ is the estimated proportion of known-cause dead whales where the death is attributed to vessel strikes $(a=12 / 17$, Moore et al. 2004), and $Q(0.83)$ is estimated as the proportion of any group of dead right whales that were not detected (Kraus et al. 2005; $Q=$ $1-0.17)$. Uncertainties in the estimates are provided by re-sampling (bootstrap with replacement) $X$, and by recalculating both $Z_{1}$ and $Z_{2}$ and determining $\hat{\mu}$ (Eq. 1) where $n$ is replaced with $Z_{1}$ or $Z_{2}$.

Vessel and right whale relative encounter probability. Whale data along the USA east coast: Large-whale aerial- and vessel-survey data among various rightwhale habitats surveyed since 1978 for the east coast of the USA were secured from the North Atlantic Right Whale Consortium (Kenney 2001, NARWC 2005). The survey-based observations were corrected to provide sightings per unit of effort (SPUE; number of right whales sighted per $1000 \mathrm{~km}$ of survey track) resolved at a 5' latitude and longitude resolution. We aggregate 
the SPUE data over the period 1983 to 2002 inclusive among 3 different right whale habitats (see Figs. 4, 5 \& 6): Cape Cod Bay (CCB); the Great South Channel (GSC); and the southern calving ground (SCG). Although they have been identified in research and policy reports as regions of considerable threat of vessel strikes to right whales, we focus on these habitats because they have not been evaluated in terms of quantifying vessel-whale encounter probabilities within and among habitats as achieved in the Bay of Fundy and Roseway Basin (Vanderlaan et al. 2008). The SPUE estimates within a region must be interpreted with caution where survey effort is low or absent in any given year. For example, effort is relatively low on Stellwagen Bank just north of Cape Cod Bay proper in the CCB habitat and to the northeast in GSC habitat. Although the sightings data are corrected for effort, we disregard potential biases that may be associated with the non-uniform geographic distribution of effort (cf. Vanderlaan et al. 2008) and rely on the $20 \mathrm{yr}$ aggregation of the SPUE data to minimize potential bias.

Vessel data along the USA east coast: We calculate vessel and whale encounter probabilities within and among the 3 regions using the International Comprehensive Ocean-Atmosphere Data Set (ICOADS, National Center for Atmospheric Research, Boulder). ICOADS is derived from the fleet of Voluntary Observing Ships (VOS); a sample of about 4000 vessels among a commercial fleet of about 45000 (Corbett \& Koehler 2003, Corbett 2004, Wang et al. 2008). ICOADS data provided vessel density estimates of vessel traffic distribution at a $6^{\prime}$ latitude and longitude resolution aggregated over a $20 \mathrm{yr}$ period (1982 to 2002 inclusive).

To match the $5^{\prime}$ right-whale data resolution we reresolved the ICOADS data to $5^{\prime}$ resolution. ICOADS vessel location data were re-sampled from $6^{\prime}$ grid cells to $1^{\prime}$ resolution using a spline interpolator, keeping total vessel-density constant over each 6 ' neighbourhood. The $1^{\prime}$ cells were then aggregated into $5^{\prime}$ cells concordant with the SPUE grid. We re-resolved the ICOADS rather than the SPUE data because the vessel location data represent a more continuous field of higher density over time (relative to SPUE) and thus can be re-sampled at the higher resolution without loss of data integrity. Re-resolving the SPUE data to a lower resolution increases uncertainty. A quantitative examination of the total vessel density and variance indicated virtually identical spatial patterns at $6^{\prime}$ and $5^{\prime}$ resolution.

Relative probability of vessel-whale encounter. We use the spatial distribution of vessels and right whales (SPUE) to quantitatively estimate the relative probability of vessel-whale encounter within and among the 3 regions. The estimates are relative because neither the SPUE nor ICOADS data provide absolute measures of whales or vessels per unit area. Moreover, the encounter probability estimates are 2dimensional (surface encounter) primarily because the SPUE measures are based on whales being observed at or near the surface. Our estimates do not explicitly address possible subsurface encounters between vessels and whales.

We use the approach detailed in Vanderlaan et al. (2008) to estimate the relative probability that a vessel and a whale will occupy (encounter each other in) a given space (grid cell, $i$ ). The aggregate SPUE estimates $\left(S P U E_{i}\right)$ provide the relative probability, at $5^{\prime}$ resolution, that a whale occupies grid cell $i$ relative to other cells in a domain of $n$ cells (simplification of a 2dimensional $n_{\mathrm{X}, \mathrm{Y}}$ grid) and is calculated as

$$
P_{\text {rel }}(\text { Whale })_{i}=\frac{S P U E_{i}}{\sum_{i=1}^{n} S P U E_{i}}
$$

Similarly, we estimate the relative probability, at $5^{\prime}$ resolution, that a vessel $\left(V_{i}\right)$ occupies grid-cell $i$ and is calculated as

$$
P_{\text {rel }}(\text { Vessel })_{i}=\frac{V_{i}}{\sum_{i=1}^{n} V_{i}}
$$

Using Eqs. (5) and (6) above, the relative probability that a vessel and a whale will encounter each other in grid-cell $i$ is then calculated as

$$
P_{\text {rel }}(\text { Encounter })_{i}=\frac{P_{\text {rel }}(\text { Whale })_{i} \cdot P_{\text {rel }}(\text { Vessel })_{i}}{\sum_{i=1}^{n}\left(P_{\text {rel }}(\text { Whale })_{i} \cdot P_{\text {rel }}(\text { Vessel })_{i}\right)}
$$

where the $P_{\text {rel }}(\text { Encounter })_{i}$ estimates are normalized such that their sum across the grid is equal to 1 .

Relative encounter probabilities are calculated for each of the 3 regions. To compare among the 3 regions we modify (7) and calculate regionally normalized estimates:

$$
P_{\text {rel }}(\text { Encounter })_{i}=\frac{P_{\text {rel }}(\text { Whale })_{i} \cdot P_{\text {rel }}(\text { Vessel })_{i}}{\sum_{i=1}^{m}\left(P_{\text {rel }}(\text { Whale })_{i} \cdot P_{\text {rel }}(\text { Vessel })_{i}\right)}
$$

where $m=\left(n_{\mathrm{CCB}}+n_{\mathrm{GSC}}+n_{\mathrm{SCG}}\right)$.

Habitual traffic pattern (HTP). We define the HTP as the self-determined principle path, route, or lane in the ocean traveled by vessels and connect one or more geographic locations, such as a traffic separation scheme (TSS; not self-determined) and a port. Within an HTP there are many more vessels than in areas adjacent thereto. Vessels may enter or exit an HTP at various points on the way from or to a port or TSS. In our analyses, HTPs were quantitatively identified as an exact number of adjoining grid-cells with high $P_{\text {rel }}($ Vessel) estimates that can be subtracted from the 
background estimates. This allows us to assess the consequences of shifting vessel traffic to an alternate and virtual HTP designed to reduce $P_{\text {rel }}$ (Encounter).

To quantify the existing HTP within the GSC region, we generated a bounding polygon encompassing the traffic pattern. Treating this area as a smooth surface (with longitude as the $x$, latitude as the $y$, and vessel density as the $z$ variables respectively) we then computed the slope (rate of change in vessel density between a cell and its 8 neighbours) and aspect (the direction of change). Using vessel density, slope and aspect for each grid cell, we used a maximum likelihood classifier to create classes of cells with similar characteristics. We identified a subset of these classes that characterized the HTP and by inspection removed individual cells from these classes that appeared geographically independent of the HTP. Grid cells identified as part of the HTP were then 'removed' from the data. The resulting null space was filled by using a thin-plate splineinterpolation of the neighbouring grid cells just outside the HTP; i.e. to create a smooth, continuous background density of vessels. The difference between the smooth background and the original data was then used to determine the vessel-density in the HTP above background, referred to as the $\mathrm{HTP}_{\mathrm{d}}$ (density). To simulate shifting of the HTP to a new location of identical area, the $\mathrm{HTP}_{\mathrm{d}}$ was uniformly added to cells identified as the virtual HTP, thereby keeping $\mathrm{HTP}_{\mathrm{d}}$ constant. This required the addition of virtual vessels to conserve the traffic density along longer (virtual) routes, because the VOS fleet generally provide data to ICOADS at regular intervals (e.g. every 4, 12, or $24 \mathrm{~h}$; Wang et al. 2007); this means that vessels of similar speed and traveling a greater distance can be expected to report proportionally more often. Therefore, we increased $\mathrm{HTP}_{d}$ proportionally to the additional length of the virtual HTP to avoid under-representation of the same number of vessels rerouted along a longer track.

\section{RESULTS}

\section{Temporal and regional probabilities of vessel strikes}

Our model provides estimates, with approximately $100 \%$ confidence, that as many as $7\left(P_{\max }=0.26\right.$ at 2 strikes) and $12\left(P_{\max }=0.17\right.$ at 5 strikes $)$ large whales were struck each year over the periods of 1972 to 1979 and 1980 to 1990, respectively. The CDF shows a $\sim 50 \%$ chance of $>17$ strike reports annually $\left(P_{\max }=\right.$ 0.095 at 17 strikes) with an upper bound of 29 strikes over the 1991 to 1998 period and $~ 50 \%$ chance of $>14$ strike reports annually $\left(P_{\max }=0.10\right.$ at 14 strikes $)$ with an upper bound of 26 strike reports over the 1999 to 2002 periods. Together, these estimates demonstrate a
3- to 4-fold increase in the number of large-whale vessel-strikes, where the CDF initially reaches 1 , from the early 1970s to the early 2000s.

In evaluating only the regional east coast of the USA data over the same three decades (Fig. 2b), we again estimate a systematic 3 - to 6 -fold increase over time in the number of large-whale strike reports. An examination of the remaining worldwide data again reveals a 3 - to 4 -fold increase in strike reports (Fig. 2c). For right whales only, along the North American east coast, we observe a 2-fold increase over time (Fig. 2d).

Among the $\hat{\mu}$ estimates and their sequential ratios among adjacent periods (1972 to $1979 ; 1980$ to 1990 ; 1991 to $1998 ; 1999$ to 2002 ), we observe that the worldwide vessel-strike report-ratios change from 2.3 to 3.3 and then to 0.83 . This indicates that the number of vessel-strike reports increased from the 1970 s to the 1980 s, increased again and at a higher rate from the 1980s to the 1990s, and then stabilized (or slightly decreased) during the 1990s and 2000s. A similar pattern is observed for the US east coast where initially higher sequential ratios of $\hat{\mu}$ change from 3.2 to 3.4 and thus represent a continuing inter-decadal increase in strike reports. As with the worldwide pattern, strike reporting rates are similar in the latter decades. The worldwide data, less those derived from the USA east coast, also show a similar pattern with the ratios of $\hat{\mu}$ changing from 1.9 to 3.2 and then stabilizing near 1 (0.92).

Increasing strike rates (illustrated by the inter-period ratios above) and the CDFs (Fig. 2) indicate that the vessel strike reports for the USA east coast strongly influence worldwide strike reports during the 1970s and 1980 s; as initially indicated in Fig. 1. Increasing estimates from the 1980s to the 1990s are similar among the regional data and indicate that the increase in strike reports from the USA east coast is reflected in the worldwide data. Consistent with this interpretation is the fact that the relative change for the two most recent periods is near 1.0 (0.83 worldwide and 0.72 east coast USA), indicating convergence in the greater number of strike reports annually.

While the number of whales struck annually on a worldwide basis for the 2 most recent periods are different when based on the bootstrap technique and the derived $\hat{\mu}$ values (Student's $t$-test, $\mathrm{p} \ll 0.0001$ ), the $95 \%$ confidence interval associated with the CDF for 1991 to 1998 is within that estimated for 1999 to 2002. Similar results are observed for the USA east coast. The probability of observing zero right-whale vesselstrike reports annually is 0.11 (95\% CI: 0.068-0.16). The probability of observing 6 or fewer vessel-strikes annually is virtually $1(0.99 ; 95 \%$ CI: 0.98 to 1.0$)$. In general, the confidence intervals around the bootstrap estimates in the latter periods are large and overlap, confirming that the difference in estimates between 

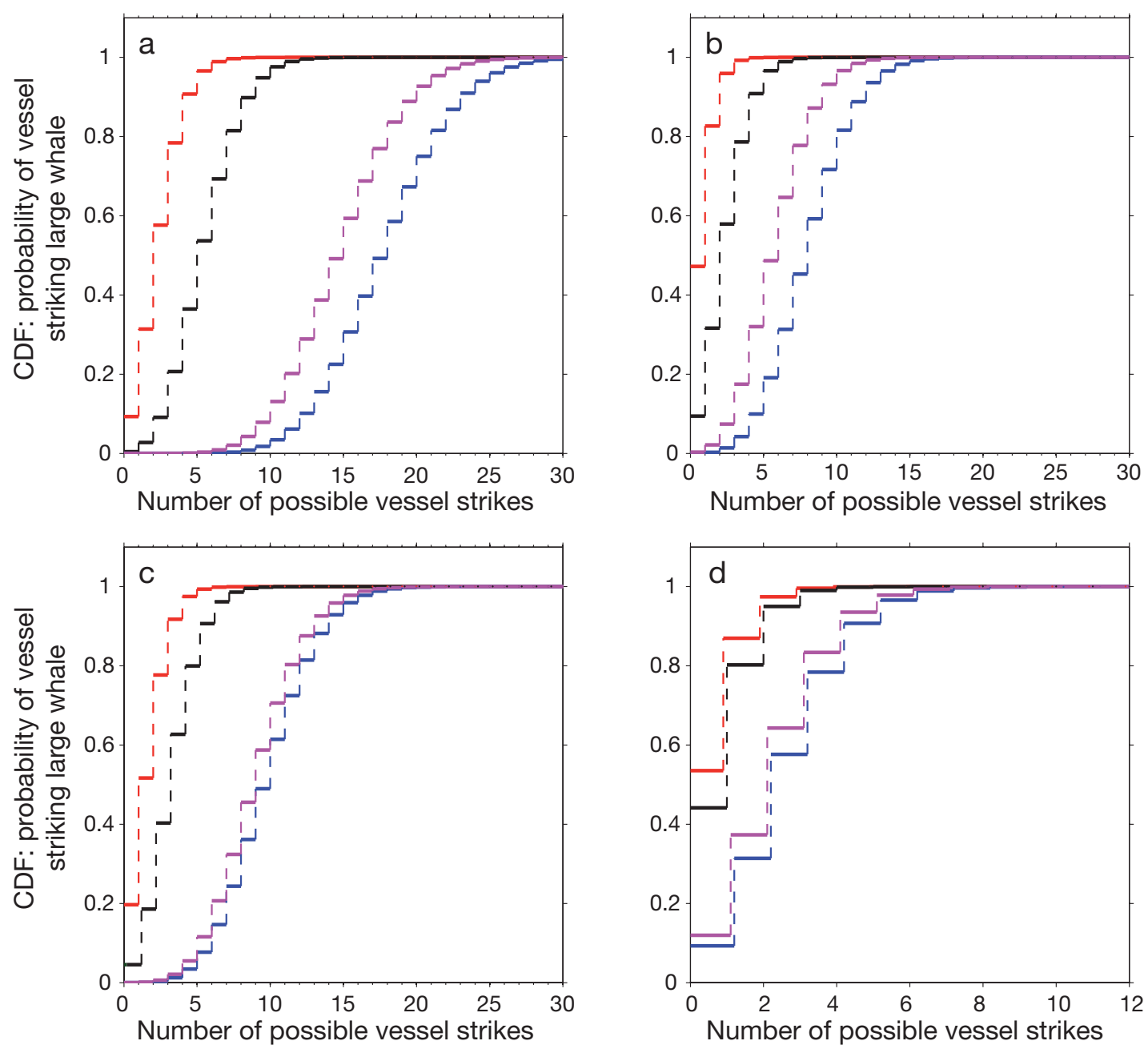

Fig. 2. Cumulative distribution functions (CDF) of annual vessel-strike probabilities for: (a) all large whales worldwide; (b) all large whales along the US East coast; $(\mathrm{c})$ all large whales worldwide excluding US East coast; (d) right whales along East coasts of USA and Canada (including recent; 2003 to 2006 inclusive). Each CDF represents 1 of the 4 periods (inclusive) of analyses: 1972 to 1979 (red); 1980 to 1990 (black); 1991 to 1998 (blue); and 1999 to 2002 (magenta) except in (d) where the period is 1999 to 2006

the 2 most recent periods is less significant than the differences between these and earlier decades.

The $\hat{\mu}$ values in Fig. $2 d$ represent the minimum and maximum range of the expected number of rightwhale vessel-strikes per year throughout their NW Atlantic habitat. When we focus on strikes that resulted in the death of a right whale and correct the $\bar{\mu}$ parameter for the vessel-strike mortality-detection rate and the undetermined causes of death (Table 1, Fig. 3a,c), the number of possible deaths resulting from vessel strike increases from 5 ( $P_{\max }=0.40$ at 0 strikes) to $19\left(P_{\max }=0.13\right.$ at 9 strikes). The average value of $\hat{\mu}$ (Table 1, Fig. 3b,d) increases from 0.91 (95\% CI: 0.58 to $1.3)$ to 9.7 (95\% CI: 9.4 to 10 ). These corrections provide conservative upper-bound estimates of the probability of a specific number of annual vessel strikes that result in a right-whale death. The estimates may be used to predict, with uncertainty, a specific number of annual vessel strikes in the near future assuming that vessel number, speed and navigation patterns and the right whale population size remain relatively stable.

\section{Relative probability of vessel and right whale encounter}

The greatest probabilities of observing a right whale, $P_{\text {rel }}$ (Whale), in the CCB region occur within portions of Cape Cod Bay proper (Fig. 4a). The greatest probability of observing a vessel, $P_{\text {rel }}($ Vessel), is also highest within the Bay and near the approaches to the port of Boston. There are two poorly resolved HTPs, each extending through the mandatory ship reporting system (MSRS) area; one to the north-northeast and the other to the 

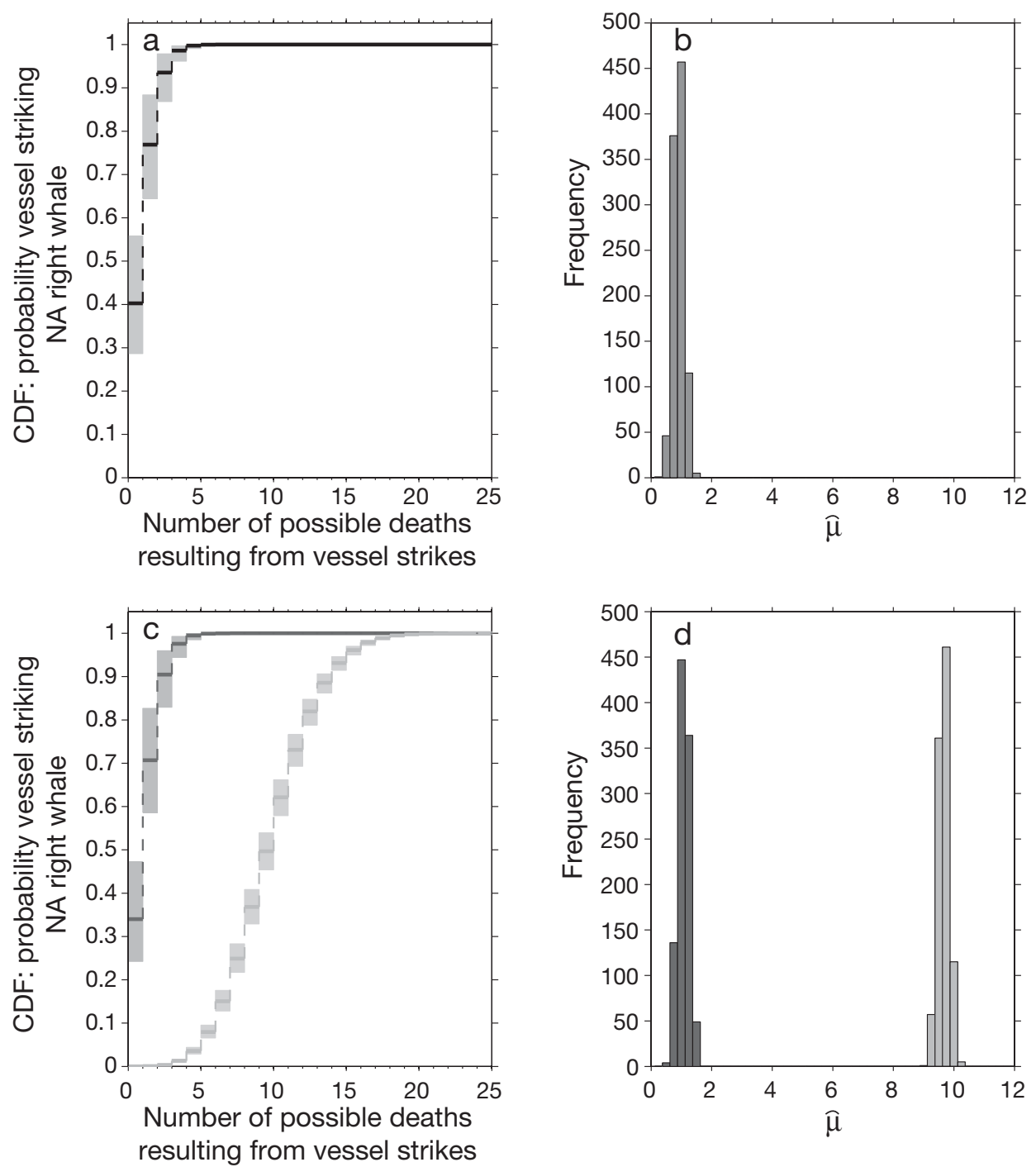

Fig. 3. Cumulative distribution functions $(\mathrm{CDF}$ a \& c) for the probability of a vessel-strike death over the period 1991-2002 inclusive for North Atlantic (NA) right whales along the east coast of the USA and Canada estimated using the mean bootstrapped value of $\hat{\mu}$ (black line) and its corresponding 95\% confidence interval (shaded), and based on (a) reported strike deaths and (c) reported strike deaths adjusted for deaths of undetermined cause (dark gray) and adjusted for both the mortality-detection rate and deaths of undetermined cause (light gray). The corresponding frequency distribution of the bootstrapped $\widehat{\mu}$ values are provided in (b) and (d)

Table 1. Estimates of the Poisson parameter, $\hat{\mu}$, used to calculate the probability $(P)$ of exactly zero and of $k$ lethal vessel strikes to right whales in the NW Atlantic, where $k$ represents the most likely number of deaths from vessel-strikes based on reported strikes over the period 1991 through 2002 and as adjusted for unknown deaths (1st approximation) and adjusted for both detection rate and unknown deaths (2nd approximation)

\begin{tabular}{|lccccc|}
\hline Correction to estimates & $\hat{\mu}$ & $P(x=0)$ & \multicolumn{2}{c|}{$P_{\max }(x=k)$} \\
& & & $k$ & $P(x=k)$ \\
\hline No correction & 0.91 & 0.40 & 0 & 0.40 \\
1st approximation based on Eq. (3) & 1.1 & 0.34 & 1 & 0.37 \\
2nd approximation based on Eq. (4) & 9.7 & 0.00010 & 9 & 0.13 \\
& & & & \\
\hline
\end{tabular}

northeast (Fig. 4b). As a result, the greatest probability of a vessel-whale encounter, $P_{\text {rel }}$ (Encounter), is within Cape Cod Bay and to a lesser extent, by an order of magnitude, to the northeast in the Gulf of Maine (Fig. 4c).

The highest $P_{\text {rel }}($ Whale) estimates in the GSC region are distributed along the southern reaches of the Boston TSS, within the Great South Channel region of the MSRS area and along the northern shelf-break of Georges Bank (Fig. 5a). The $P_{\text {rel }}($ Vessel) estimates are 


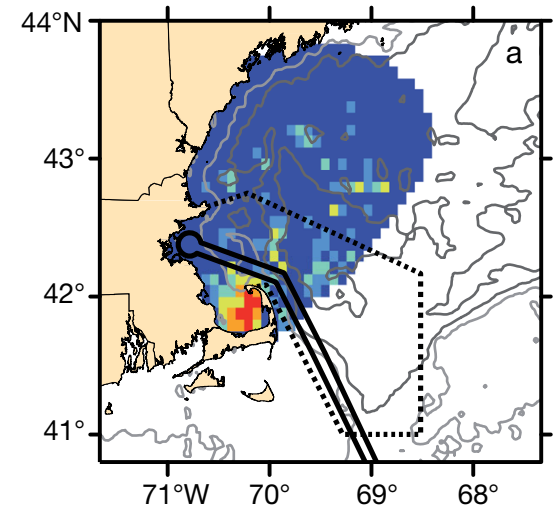

$P_{\text {rel }}($ Whale $)$

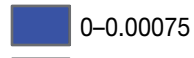

$>0.00075-0.0018$

$>0.0018-0.0034$

$>0.0034-0.022$

$>0.022-0.050$

$>0.050-0.15$

$P_{\text {rel }}($ Vessel)

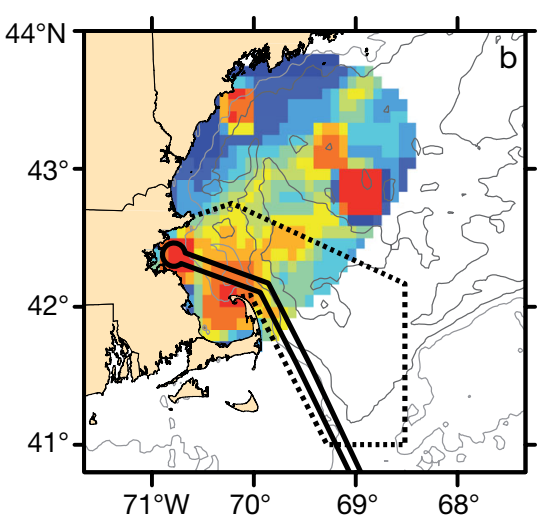

0-0.00046

$>0.00046-0.00082$

$>0.00082-0.0010$

$>0.0010-0.0012$

$>0.0012-0.0014$

$>0.0014-0.0016$

$>0.0016-0.0017$

$>0.0017-0.0023$

$>0.0023-0.0035$

$>0.0035-0.023$

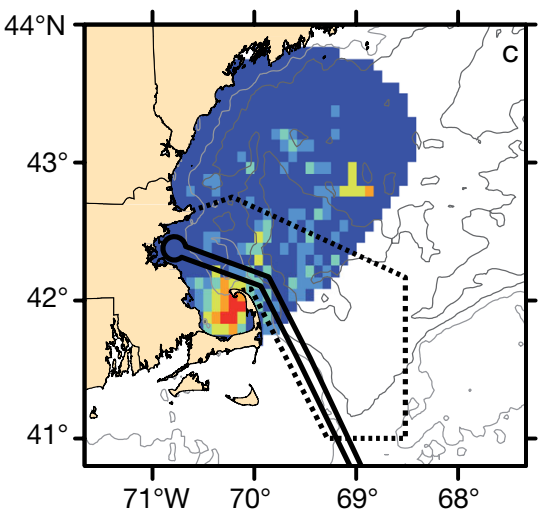

$P_{\text {rel }}($ Encounter $)$

0-0.00020

$>0.00020-0.00085$

$>0.00085-0.0034$

$>0.0034-0.026$

$>0.026-0.042$

$>0.042-0.15$

Fig. 4. Bathymetric $(50,100,200 \mathrm{~m})$ charts illustrating the relative probability, at 5 ' resolution, of observing (a) a North Atlantic right whale, (b) a vessel, and (c) a vessel-whale encounter in the Cape Cod Bay and Stellwagen Bank right-whale habitat. The mandatory ship reporting area is outlined (dashed line) as is the International Maritime Organization traffic separation scheme for the port of Boston (solid black line)

highest along 2 well-defined HTPs, each extending from the entrance of the New York TSS; one to the northeast approaching the Bay of Fundy and the other east and then north along the southern perimeter of Georges Bank (Fig. 5b). These HTPs illustrate higher traffic density relative to the Boston TSS because they
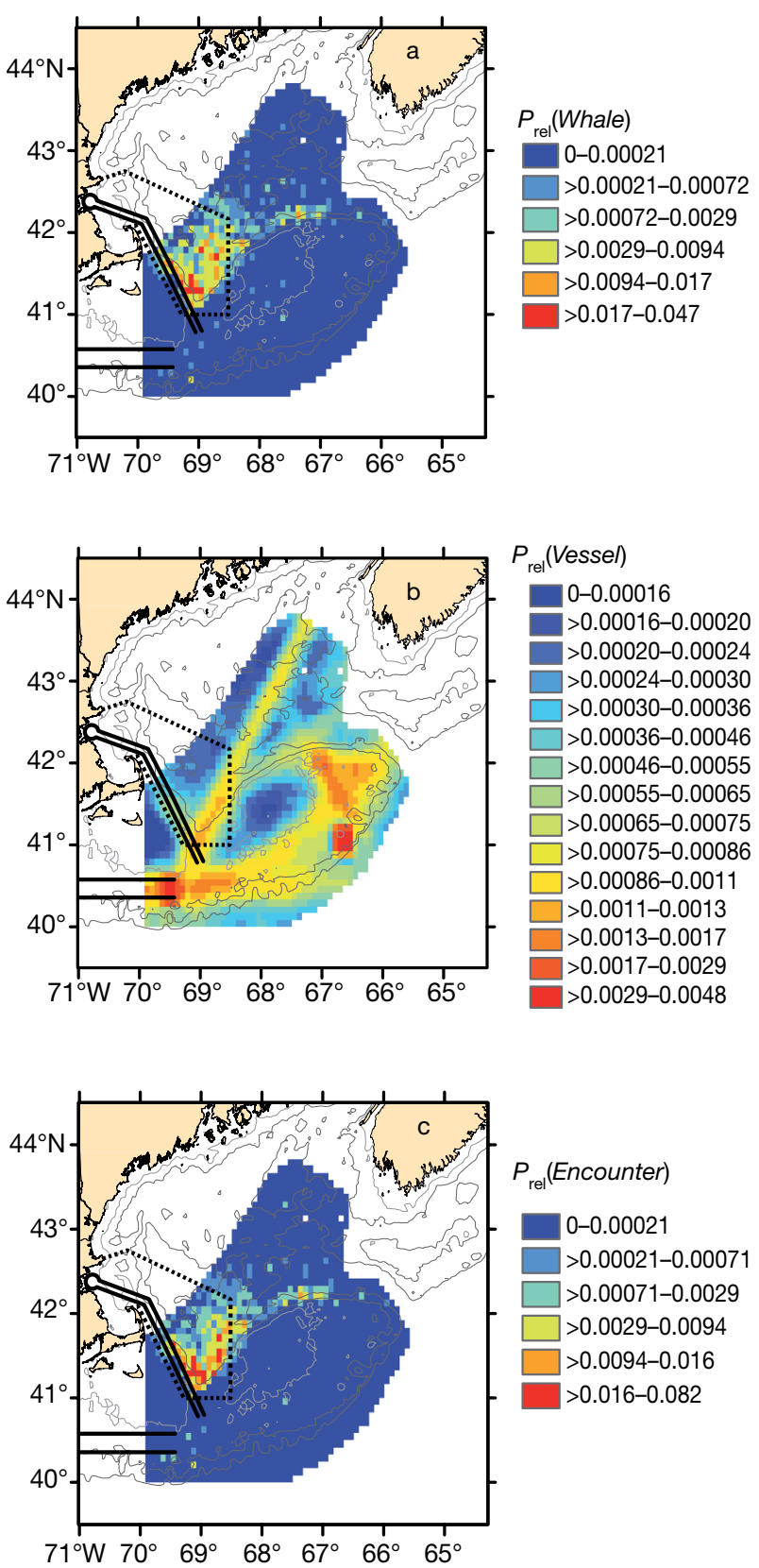

Fig. 5. Bathymetric $(50,100,200 \mathrm{~m})$ charts illustrating the relative probability, at $5^{\prime}$ resolution, of observing (a) a North Atlantic right whale, (b) a vessel, and (c) a vessel-whale encounter in the Great South Channel habitat. The mandatory ship reporting area is outlined (dashed line) as are the International Maritime Organization traffic separation schemes for the ports of Boston and New York (solid black lines)

include vessels navigating to and from ports other than Boston. The consequence of the above distributions is that the highest $P_{\text {rel }}$ (Encounter) estimates are distributed along the southern extent of the Boston TSS and along the HTP to the northeast and each is encompassed by the MSRS area (Fig. 5c). 

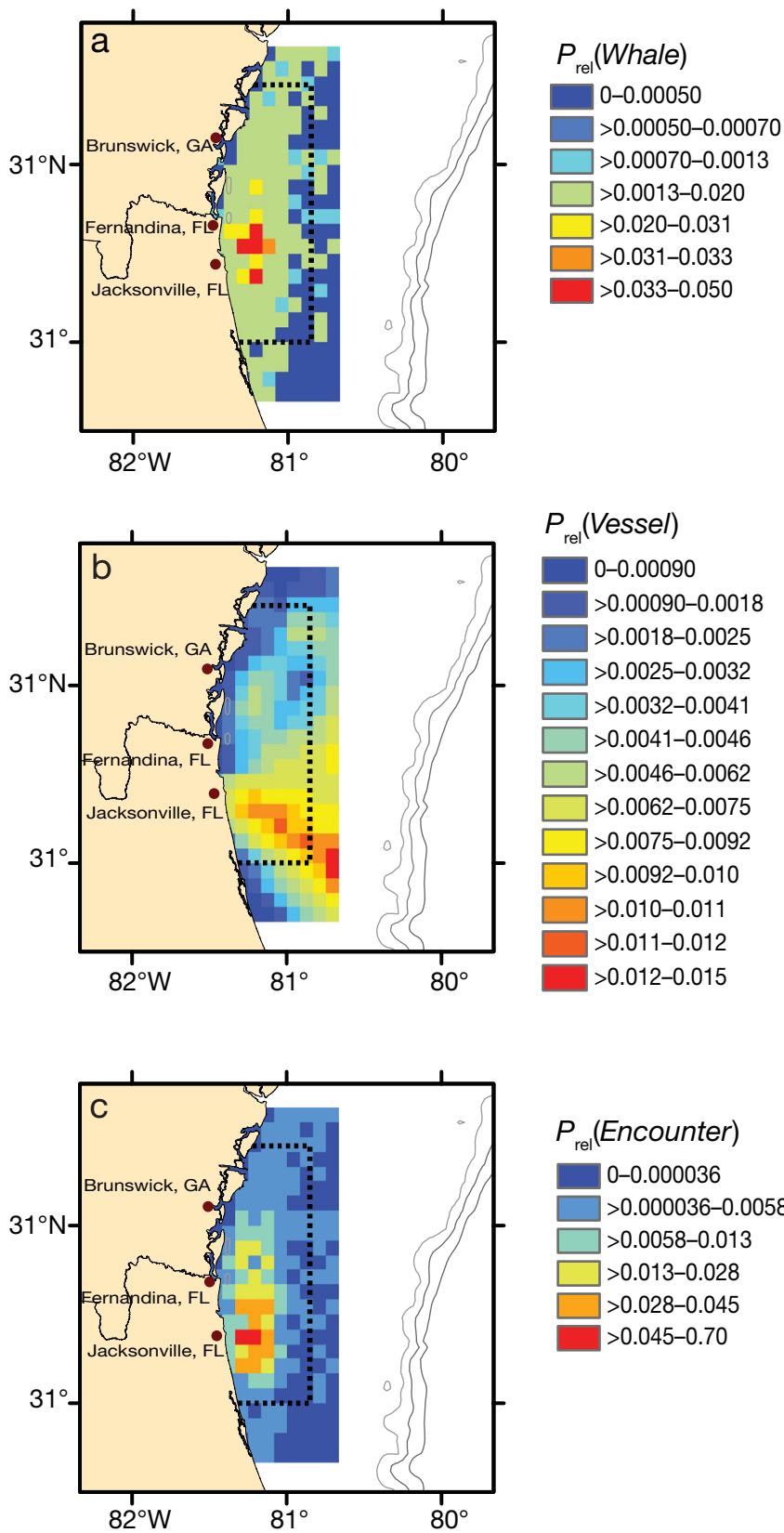

Fig. 6. Bathymetric $(50,100,200 \mathrm{~m})$ charts illustrating the relative probability, at 5 ' resolution, of observing (a) a North Atlantic right whale and (b) a vessel, and (c) a vessel-whale encounter in the southern calving ground habitat. The mandatory ship reporting area for the southern calving ground is outlined (dashed line) and includes the ports of Jacksonville and Fernandina (Florida), and Brunswick (Georgia)

In the SCG region off Jacksonville, the highest $P_{\text {rel }}($ Whale) estimates are located near the centre of the MSRS area (Fig. 6a) and slightly north of a welldefined HTP (high $P_{\text {rel }}($ Vessel)) that extends southeast from the port of Jacksonville (Fig. 6b). As the $P_{\text {rel }}($ Whale) estimates are generally uniform to the
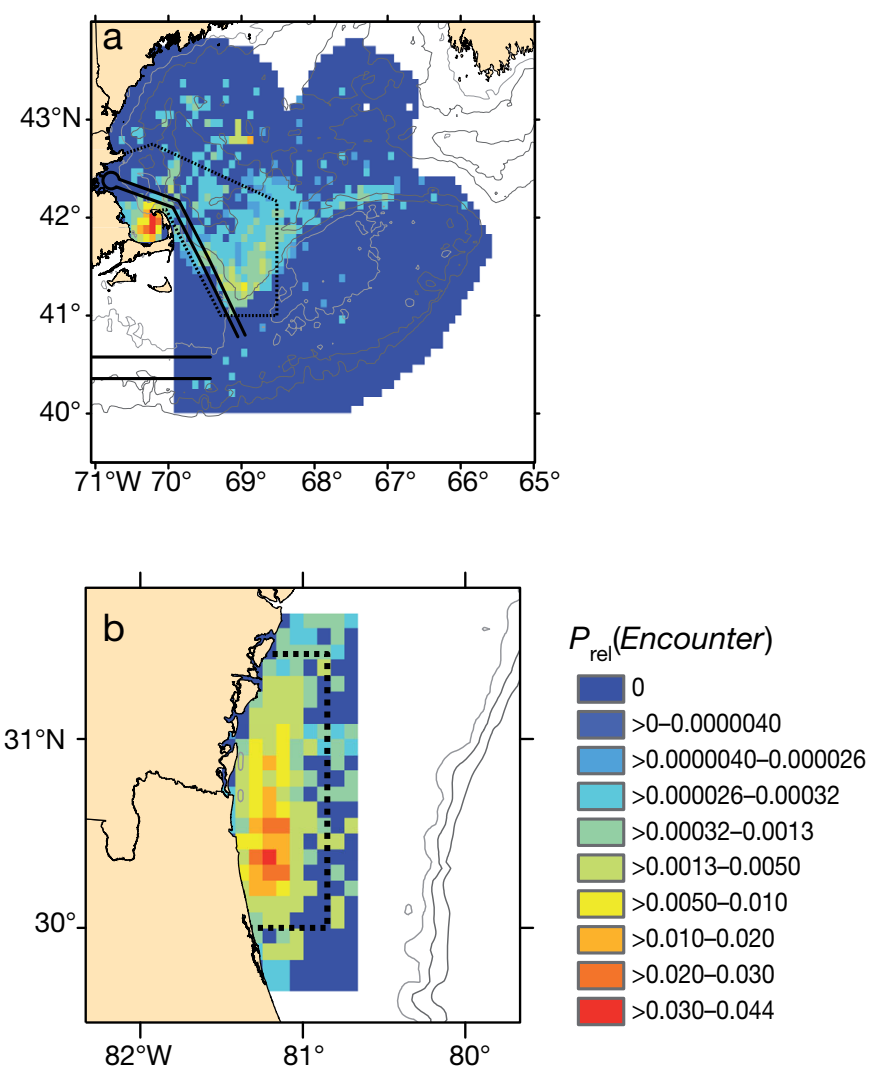

Fig. 7. Bathymetric $(50,100,200 \mathrm{~m})$ charts illustrating the relative probability of a vessel-whale encounter in (a) the Cape Cod Bay and Great South Channel habitats and in (b) the southern calving ground habitat where probabilities have been standardized for direct comparison among habitats. The mandatory ship reporting areas are outlined (dashed lines) as are the International Maritime Organization traffic separation schemes for the ports of Boston and New York (solid black lines)

north and south of the high-probability node, the highest $P_{\text {rel }}$ (Encounter) estimates (Fig. 6c) are located at the northwest extent of the HTP (Fig. 6b) near the approaches to Jacksonville.

When the $P_{\text {rel }}$ (Encounter) estimates are standardized across all 3 analytical domains and are compared, we observe the greatest probability of a vessel strike is in the SCG region where the cumulative standardized $P_{\text {rel }}$ (Encounter) is 0.57 (Fig. 7). Estimates for the CCB and GSC regions are lower at 0.36 and 0.079, respectively. Within the GSC, the regionallystandardized estimates are elevated along the margins of the Nantucket Shoals and Georges Bank where they intersect the Great South Channel and the southern extent of the Boston TSS, but they are an order of magnitude lower than in the SCG. This GSC region lends itself to re-routing options more so than the relatively confined CCB and SCG regions where vessel routing options are limited. Therefore, we con- 
sider HTP-shift options for the GSC region. Moreover, the data we use (ICOADS) is more representative of vessel traffic because it includes vessels that transit the GSC outside the MSRS area and thus are not required to report.

\section{Shifting habitual traffic patterns}

We examine one vessel-pattern shift for one primary HTP in the GSC region (Fig. 5b), beginning near $43^{\circ} 40^{\prime} \mathrm{N}, 67^{\circ} 20^{\prime} \mathrm{W}$ and extending approximately $210 \mathrm{~nm}(390 \mathrm{~km}) \mathrm{SW}$ to near $40^{\circ} 30^{\prime} \mathrm{N}, 69^{\circ} 20^{\prime} \mathrm{W}$. Traffic between the New York TSS and the Bay of Fundy that transits the GSC could be re-rerouted around the eastern tail of Georges Bank. This option is chosen based on minimizing $P_{\text {rel }}$ (Encounter) while taking advantage of existing adjacent or adjoining HTPs and at the same time recognizing the Boston and New York TSS and avoiding bathymetric limitations (i.e. shoals on Georges Bank) that compromise safe voyage.

For the GSC region the vessels provided by the $\mathrm{HTP}_{\mathrm{d}}$ estimate were shifted to create the virtual HTP that is $\sim 266 \mathrm{~nm}(\sim 493 \mathrm{~km})$ in length. Accordingly, vessel density in the $\mathrm{HTP}_{\mathrm{d}}$ was increased uniformly to accommodate the increase in length. The width of the virtual HTP was designed to mirror that of the existing HTP; i.e. 3 to 5 grid cells.

Quantitative shifting of vessels from the existing HTP to the virtual HTP (Fig. 8a) in the GSC region achieves a substantial reduction in the probability of vessel-right whale encounters by limiting vessel traffic though the region where $P_{\text {rel }}$ (Encounter) estimates are highest (Fig. 5c). With this re-routing option the virtual HTP shifts traffic well to the east with a northsouth orientation before turning east-west to merge with the existing HTP at the eastern approach to the New York TSS (Fig. 8a). This shift achieves an overall $39 \%$ reduction in $P_{\text {rel }}$ (Encounter) across the entire GSC study region. Residuals show that estimates are substantially decreased (green to blue in Fig. 8b) across a large area within and to the north the Great South Channel. Some isolated increases in $P_{\text {rel }}$ (Encounter) occur near the shelf break northeast of Georges Shoals $\left(\sim 67^{\circ} \mathrm{W}\right)$.

\section{DISCUSSION}

Historical data concerning vessels striking large whales confirm that globally, and along the east coast of the USA, the rate of reported strikes has been increasing over the last 4 decades and the variation in underlying factors leading to vessel-strike reports may have stabilized in recent years (1991 to 2002).
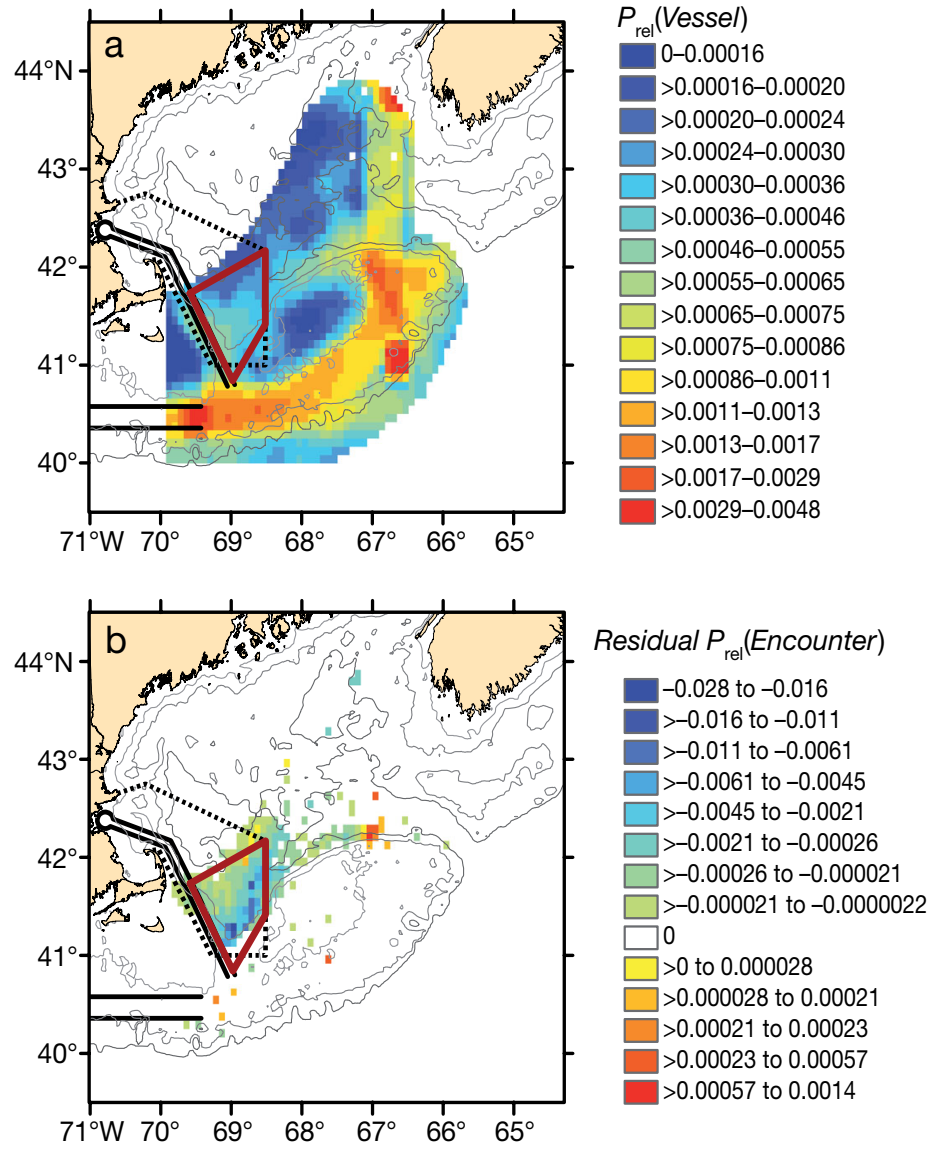

Fig. 8. Bathymetric $(50,100,200 \mathrm{~m})$ charts illustrating 5 ' resolution of (a) relative probability of observing a vessel and (b) the residual absolute probabilities of vessel-whale encounter (existing HTP relative probabilities minus the virtual HTP relative probabilities; green/blue: reduced probability; yellow/red: increased probability). The mandatory ship reporting area is outlined (dashed line) as are the International Maritime Organization (IMO) traffic separation schemes for the ports of Boston and New York (solid black lines). The approved IMO Area to be Avoided for the Great South Channel is outlined (solid dark red)

Although our analyses cannot rule out increased detection and reporting or significant increases in whale population growth rate, the increase in strike reporting is most parsimoniously explained by fleetwide increases in number, speed, and size of vessels (see 'Introduction' and Fig. 1). Using only the contemporary strike reporting rate as a basis, we predict with $60 \%$ certainty that 1 or more North Atlantic right whales will be reported annually as killed by vessel strike; this is essentially consistent with contemporary observations. However, when we adjust for deaths of undetermined cause $\left(Z_{1}\right)$ and including mortalitydetection rate $\left(Z_{2}\right)$, we predict that at least 5 right whales will be struck and killed by a vessel each year with $90 \%$ certainty. The same adjustments lead to the 
measurable probability of as many as 20 right whales being struck and killed; assuming the proportion of vessel-strike deaths is the same for the detected and undetected deaths. It is readily apparent that without modified vessel navigation, the chances of annually observing zero strikes is zero for all large-whale species globally and is systematically approaching zero for North Atlantic right whales. Moreover, bounding the range of predicted strikes using our $Z_{1}$ and $Z_{2}$ corrections, our model provides credible evidence that reported strikes underestimate the actual number of struck whales (Fig. 3).

The successful recovery of right whales depends upon a substantial reduction in vessel strikes (e.g. Caswell et al. 1999, Fujiwara \& Caswell 2001, Kraus et al. 2005). The Poisson modeling approach developed above can be used to predict the expected change in vessel strikes (and associated mortality) stemming from policy action. For example, if strike reporting data were sufficient for estimating $\hat{\mu}$ in a given study area such as the GSC, mitigation of $P_{\text {rel }}$ (Encounter) through shifting vessel traffic as outlined above would lead to an expected $40 \%$ reduction in $\hat{\mu}$ (reported right-whale vessel-strikes) and consequently a reduced premature mortality among right whales. Further, the model assumption of a historically constant whale population size could be adjusted to account for changes in whale population size, though the uncertainties in the latter are large (IWC 2001). Thus, the methodology can evaluate the relative benefits of focused strike mitigation measures among those areas where vessels and right whales have a high probability of encounter as well as where vessel speed is expected to be high (e.g. some distance from a port). From a right whale conservation perspective, decreasing the probability of a strike by re-routing large vessels may be preferable to reducing vessel speed simply because it minimizes the probability of a strike, as opposed to maintaining strike probability and minimizing strike lethality (Vanderlaan et al. 2008).

The methods we employ here in assessing encounter probabilities and the effects of shifting habitual traffic patterns can be applied to other large whale species. For example fin, humpback, and minke whales along the east coast of the USA are victims of vessel strikes. Many of these species frequent right whale habitat; therefore the proposed shift in the HTP has the potential to differentially impact other whales. Although it appears from a qualitative examination that the rerouting discussed for the GSC region above should achieve a reduction in probability of vessels encountering these other species (Fig. 9), the effects of shifting HTPs must be evaluated quantitatively to ensure that proposed shifts do not simply transfer the threat of vessel strikes to other species (Vanderlaan et al. 2008).

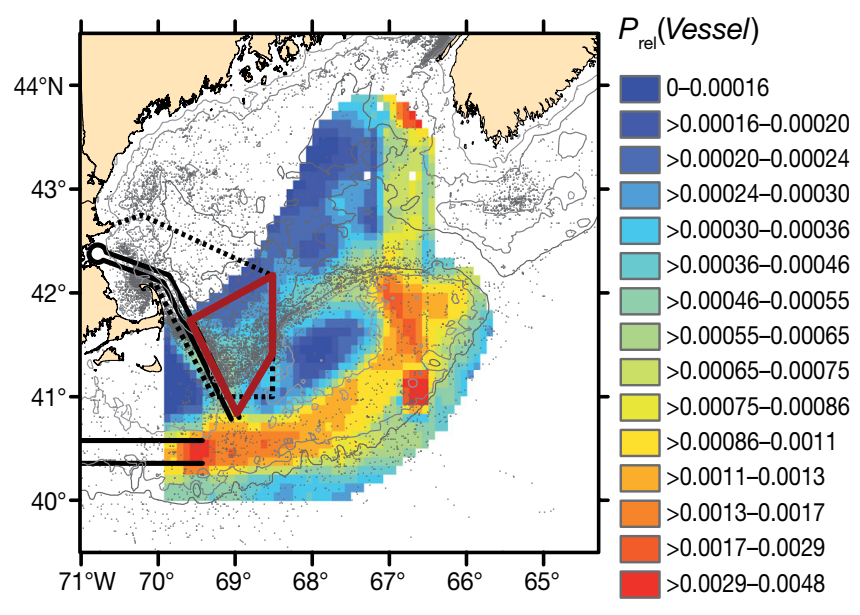

Fig. 9. Bathymetric $(50,100,200 \mathrm{~m})$ chart illustrating the $5^{\prime}$ resolution relative probability of observing a vessel based on virtual HTP showing the locations (gray dots) of survey-based sightings of all large whales (excluding right whales) 1978 to 2002 inclusive. The mandatory ship reporting area is outlined (dashed line) as are the International Maritime Organization (IMO) traffic separation schemes for the ports of Boston and New York (solid black lines). The approved IMO Area to be Avoided for the Great South Channel is outlined (solid dark red)

Vessel-traffic management options can be quantitatively developed, compared, improved and optimized such that practical and feasible solutions can be identified. Speed restrictions may apply and have merit when HTP-shifts are prohibited by bathymetry or where a shift in vessel traffic should substantially increase vessel encounters with other whale species. Speed reductions appear to be the primary option for regions in close proximity to ports where vessels and right whales are concentrated together-as in the CCB and SCG regions. In these regions, we cannot easily identify alternative traffic routes other than seasonal port diversions and thus turn to the recently applied (09 Dec 2008; NOAA 2008b) vessel-speed restrictions as being more practical for reducing the lethality acknowledging that the encounter probabilities will remain high, but not higher (see Vanderlaan \& Taggart 2007 regarding encounter probability as a function of speed).

The HTP shift option illustrated in Fig. 8 offers a feasible and practical example of a shift in traffic patterns in the GSC region that, if implemented, should result in a measurable $(\sim 40 \%)$ reduction in the number of vessel and right whale encounters. In the GSC region there have been proposals to seasonally restrict vessel speeds to $\leq 10$ knots $\left(18 \mathrm{~km} \mathrm{~h}^{-1}\right)$ and to create an IMO-sanctioned Area to be Avoided (ATBA; IMO 2008a), both of which have been approved (NOAA 2008b, IMO 2008b). As of December 2008, new seasonal speed restrictions apply within the Off-Race- 
Point and the Great-South-Channel Seasonal Management Areas (ORP-SMA and GSC-SMA; NOAA 2008b) that envelope most of the area where high vesselwhale encounter probabilities exist in our GSC study region (Fig. 7a).

The re-routing option we propose here, with the virtual HTP from the north and around Georges Bank (Fig. 8a), is approximately $56 \mathrm{~nm}$ longer than the existing HTP (Fig. 5b). One would logically expect that vessels would navigate westward across the top of the GSCSMA or south-westward across the top of the adopted ATBA. However, vessels that opt to navigate north of the GSC-SMA and the ORP-SMA or the adopted ATBA and then join the Boston TSS toward the New York TSS (and vice versa) face having to comply with the seasonal 10 knot speed restriction in most of the Boston TSS. From a seasonal perspective, the optimum routing would be the longer but faster virtual HTP that we propose. For example, vessel navigating at 15, 20 or 25 knots would take $17.7,13.3$ or $10.6 \mathrm{~h}$ to complete the virtual HTP route respectively. Those opting to transit the GSC-SMA at 10 knots (and at 15, 20 or 25 knots elsewhere) would take $18.5,17.2$ and $16.4 \mathrm{~h}$, respectively, to complete the route; i.e. 5, 29 and $55 \%$ increases in transit time respectively over that for the virtual HTP. We predict that if vessel operators comply with the navigation conditionals adopted by the IMO (IMO 2008b) and with the new speed restrictions detailed by NOAA (2008b), our virtual HTP (Figs. 8a \& 9) will soon emerge as the new traffic pattern, at least on a seasonal basis.

Acknowledgements. We thank the North Atlantic Right Whale Consortium, National Oceanic and Atmospheric Administration, US Coast Guard and Army Corps of Engineers, the Environment Canada Habitat Stewardship Programme, the World Wildlife Fund Canada and Environment Canada Endangered Species Research Fund, Fisheries and Oceans Canada, S. Haney and the Canadian Whale Institute, and the Natural Sciences and Engineering Research Council of Canada for supporting our research. Special thanks to our Ship Strike Advisory Group: M. Brown, D. Chapman and A. Knowlton. Additional thanks to G. Herbert, H. Kite-Powell, K. Lagueux, A. Serdynska, K. Smedbol, C. C. Smith, J. Thomas, P. Turner, B. Wellock, and M. Zani for their insights and advice and assistance. We thank the anonymous referees for advice and critiques.

\section{LITERATURE CITED}

ACCOBAMS (Agreement on the conservation of cetaceans of the Black Sea, Mediterranean Sea and contiguous Atlantic area) (2007) Resolution 3.14: Ship strikes on large whales in the Mediterranean Sea. ACCOBAMS, Monaco

Aguilar A (1986) A review of old Basque whaling and its effect on the right whales of the North Atlantic. Rep Int Whal Comm Spec Iss 10:191-199

Best PB, Peddemors VM, Cockcroft VG, Rice N (2001) Mortalities of right whales and related anthropogenic factors in South Africa waters, 1963-1998. J Cetacean Res Manag Spec Issue 2:171-176
Caswell H, Fujiwara M, Brault S (1999) Declining survival probability threatens the North Atlantic right whale. Proc Natl Acad Sci USA 96:3308-3313

> Clapham PJ, Young SB, Brownell RL Jr (1999) Baleen whales: Conservation issues and the status of the most endangered populations. Mammal Rev 29:35-60

Clemen RT, Reilly T (2001) Making hard decisions with decision tools. Duxbury Press, Belmont, CA

Cole TVN, Hartley DL, Merrick RL (2005) Mortality and serious injury determinations for large whale stocks along the eastern seaboard of the United States, 1999-2003. Northeast Fisheries Science Center Ref. Doc. 05-08. National Marine Fisheries Service, Woods Hole, MA

Cole T, Hartley D, Garron M (2006) Mortality and serious injury determinations for baleen whale stocks along the eastern seaboard of the United States, 2000-2004. Northeast Fisheries Science Center Ref. Doc. 06-04. National Marine Fisheries Service, Woods Hole, MA

Colton T (2004) Growth of the World Fleet since WWII (as compiled from Lloyds Register of Shipping, World Fleet Statistics). Maritime Business Strategies, Delray Beach, FL

Corbett JJ (2004) Marine transportation and energy use. In: CJ Cleveland (ed) Encyclopedia of energy, Vol 3. Elsevier Science, San Diego, CA, p 745-748

Corbett JJ, Koehler HW (2003) Updated emissions from ocean shipping. J Geophys Res 108(D20):4650-4666

Eyring VH, Köhler HW, van Aardenne J, Lauer A (2005) Emissions from international shipping: 1. The last 50 years. J Geophys Res 110, D17305, doi:10.1029/ 2004JD005619

Fujiwara M, Caswell H (2001) Demography of the endangered North Atlantic right whale. Nature 414:537-541

IMO (International Maritime Organization) (2003) New and amended traffic separation schemes. Ref. T2/2.07, COLREG.2/Circ.52, IMO, London

IMO (International Maritime Organization) (2007) Routing measures other than traffic separation schemes. Ref. T2OSS/2.7, SN.1/Circ.263, IMO, London

IMO (International Maritime Organization) (2008a) Routing of ships, ship reporting and related matters. Nav 54/3/1, IMO, London

IMO (International Maritime Organization) (2008b) Routing measures other than traffic separation schemes. Ref. T2OSS/2.7.1, SN.1/Circ.272, IMO, London

IWC (International Whaling Commission) (2001) Report of the workshop on status and trends of western North Atlantic Right Whales. J Cetacean Res Manag Spec Issue 2:61-87

Jensen AS, Silber GK (2003) Large whale ship strike database. NOAA Tech Memo NMFS-OPR-25. National Marine Fisheries Service, Office of Protected Resources, Silver Spring, MD

Kenney RD (2001) The North Atlantic Right Whale Consortium databases. Maritimes 43:3-5

Kite-Powell HL (2001) Shipping and ports. In: Steele JH, Turekian KK, Thorpe SA (eds) Encyclopedia of ocean sciences. Academic Press, London, p 2768-2776

Kraus SD, Brown MW, Caswell H, Clark CW and others (2005) North Atlantic right whales in crisis. Science 309: 561-562

Laist DW, Knowlton AR, Meade JG, Collet AS, Podesta M (2001) Collisions between ships and whales. Mar Mamm Sci 17:35-75

Legendre P, Legendre L (1998) Numerical ecology. Elsevier, New York

LMIS (Lloyds Maritime Information System) (2002) The Lloyds Maritime Database. Lloyd's Register-Fairplay Ltd., London 
Moore MJ, Knowlton AR, Kraus SD, McLellan WA, Bonde RK (2004) Morphometry, gross morphology and available histopathology in North Atlantic right whale (Eubalaena glacialis) mortalities (1970-2002). J Cetacean Res Manag 6:199-214

Morgan MG, Henrion M (1990) Uncertainty: a guide to dealing with uncertainty in quantitative risk and policy analysis. Cambridge University Press, New York

NARWC (North Atlantic Right Whale Consortium) (2005) North Atlantic Right Whale Consortium sightings database, 02 March 2005. New England Aquarium, Boston, MA

NOAA (National Oceanic and Atmospheric Administration) (2004) Endangered fish and wildlife, advance notice of proposed rulemaking (ANPR) for right whale ship strike reduction. Fed Regist 69:41446-41447

NOAA (National Oceanic and Atmospheric Administration) (2006) Proposed rule to implement speed restrictions to reduce the threat of ship collisions with North Atlantic right whales. Fed Regist 71:36299-36313

NOAA (National Oceanic and Atmospheric Administration) (2008a) Final environmental impact statement to implement vessel operational measures to reduce ship strikes to North Atlantic right whales, August 2008. NOAA, Office of Protected Resources, National Marine Fisheries Service, 1315 East-West Highway, Silver Spring, MD

Editorial responsibility: Sascha Hooker,

St. Andrews, UK
NOAA (National Oceanic and Atmospheric Administration) (2008b) Endangered fish and wildlife; final rule to implement speed restrictions to reduce the threat of ship collisions with North Atlantic right whales. Fed Regist 73: 60173-60191

Rosenbaum HC, Brownell RL, Brown MW, Schaeff C and others (2000) World-wide genetic differentiation of Eubalaena: questioning the number of right whale species. Mol Ecol 9:1793-1802

Vanderlaan ASM, Taggart CT (2007) Vessel collisions with whales: the probability of lethal injury based on vessel speed. Mar Mamm Sci 23:144-156

> Vanderlaan ASM, Taggart CT, Serdynska AR, Kenney RD, Brown MW (2008) Reducing the risk of lethal encounters: vessels and right whales in the Bay of Fundy and on the Scotian Shelf. Endang Species Res 4:283-297

Wang C, Lyons SB, Corbett JJ, Firestone J (2007) Using ship speed and mass to describe potential collision severity with whales: an application of the Ship Traffic Energy and Environment Model (STEEM), Paper 07-2368. Transportation Research Board 86th Annual Meeting, Transportation Research Board, Washington, DC

Wang C, Corbett JJ, Firestone J (2008) Improving spatial representation of global ship emissions inventories. Environ Sci Technol 42:193-199

Submitted: January 21, 2008; Accepted: November 25, 2008 Proofs received from author(s): February 22, 2009 